\title{
Upgrading of Blast Furnace Sludge and Recycling of the Low-Zinc Fraction via Cold-bonded Briquettes
}

\author{
Anton Andersson ${ }^{1}$ (D) Amanda Gullberg ${ }^{2} \cdot$ Adeline Kullerstedt $^{2} \cdot$ Hesham Ahmed $^{1,3} \cdot$ Lena Sundqvist-Ökvist $^{1,2}$. \\ Caisa Samuelsson ${ }^{1}$
}

Received: 14 September 2018 / Accepted: 26 April 2019 / Published online: 9 May 2019

(c) The Author(s) 2019

\begin{abstract}
Depending on the operation of the blast furnace (BF), the main outlet of zinc from the furnace is more or less via the BF dust and sludge. As the dust is recycled to the BF, the sludge has to be de-zinced prior to recycling to prevent the accumulation of zinc in the BF. De-zincing and recycling of the low-zinc fraction via sinter have been reported. However, no research concerning recycling of upgraded BF sludge via cold-bonded briquettes has been performed. In the present study, a fine-grained BF sludge with low zinc content, generated by a BF operating on a ferrous burden of $100 \%$ pellets, was upgraded using the tornado process. The process simultaneously dried and separated the BF sludge into a high-zinc and a low-zinc fraction. The feasibility of recycling the low-zinc fraction to the BF using cold-bonded briquettes was studied on a laboratory-scale BF shaft simulator. On comparison with a reference briquette, the experiments indicated that $10 \mathrm{wt} \%$ of the upgraded BF sludge can be added to the briquette without negatively affecting the reducibility. Higher additions were found to render the briquette less reduced compared to the reference under test conditions corresponding to the central part of the BF. The strength of the briquettes was not compromised with the addition of the upgraded BF sludge, and a decision to study the briquettes in the LKAB experimental blast furnace was made in order to evaluate the behavior under actual BF conditions.
\end{abstract}

Keywords Blast furnace sludge $\cdot$ Recycling $\cdot$ Upgrading $\cdot$ De-zincing $\cdot$ Cold-bonded briquettes $\cdot$ Laboratory-scale blast furnace

The contributing editor for this article was Veena Sahajwalla.

Anton Andersson

anton.andersson@1tu.se

Amanda Gullberg

amanda.gullberg@swerea.se

Adeline Kullerstedt

adeline.morcel@gmail.com

Hesham Ahmed

hesham.ahmed@ltu.se

Lena Sundqvist-Ökvist

lena.sundqvist@swerea.se

Caisa Samuelsson

caisa.samuelsson@1tu.se

1 Division of Minerals and Metallurgical Engineering, Luleå University of Technology, 97187 Luleå, Sweden

2 Swerea MEFOS, Box 812, 97125 Luleå, Sweden

3 Central Metallurgical Research and Development Institute, Helwan, P.O. Box 87, Cairo, Egypt

\section{Introduction}

Ore-based steelmaking generates a variety of residues including dusts, sludges, scales, and slags. Recycling of these residues within the process or via other applications is essential for the sustainable production of steel. Domestic environmental legislation [1] and the cost of raw material and energy continue to drive efforts toward increased recycling.

The $\mathrm{BF}$ is the dominating production unit used in orebased ironmaking. The ferrous burden is charged at the top of the furnace as agglomerates in the form of sinter and/or pellets or lump ore. Depending on which type of ferrous burden is used and the onsite possibilities of agglomeration, different options for recycling of in-plant residues by top charging are possible. When operating on sinter, in-plant residues such as dusts, mill scales, and micropelletized sludge can be incorporated in the sintering process [2]. Also, fractions of crushed basic oxygen furnace (BOF) slag can be recycled via the sinter [3]. If the steel 
plant does not have any onsite sinter plant or pellet plant, cold-bonded briquettes can be used for recycling. These types of briquettes have been used to recycle successfully BF dust, screened fines of BF additives, filter dust, pellet fines, briquette fines, coarse and fine BOF sludges, fines of the magnetic part of the desulfurization slag (desulfurization scrap), steel scrap fines, mill scales, and pickling sludges on industrial scale [4]. Injection of, e.g., BF dust in the tuyeres of the $\mathrm{BF}$, is also a possible route in addition to the recycling via top-charged agglomerates [4].

One of the residues that is generally recycled completely — with no landfill—is the dry BF dust. The BF dust is collected in the gas-cleaning equipment treating the topgas from the BF. In addition to the coarse and dry dust, a finer residue is collected; namely, the BF sludge. The BF sludge is generally not recycled despite having a chemical composition dominated by iron and carbon. There are two principal reasons why this residue is not recycled: the zinc content and the water content. In general, the zinc content is the limiting factor. Depending on how the BF is operated, the top-gas is more or less the main outlet of zinc from the furnace. Therefore, if the dust is recycled to the $\mathrm{BF}$, the sludge needs to be pretreated, for removing zinc, before recycling in order to avoid the accumulation of zinc in the BF. The effects of zinc in the BF include increased reductant rates, reduced lining life of carbonbased refractories, and scaffold formations which may lead to disturbed operation [5]. Thus, avoiding the accumulation of zinc in the furnace is essential.

Successful upgrading of BF sludge, by removing zinc and recovering iron and carbon, has been achieved using hydrocycloning [6-13], hydrometallurgical approaches [6, 7, 14-16], flotation [7], and microwave heating [17]. In the latter, the carbon was recovered by its utilization as a reducing agent during the microwave heating.

Industrial-scale recycling of the low-zinc fraction of upgraded BF sludge to the BF has been realized by incorporating it into sinter $[8,10-13]$ and cold-bonded pellets [12]. When operating a BF with a ferrous burden of $100 \%$ pellets and utilizing cold-bonded briquettes for the recycling of in-plant residues, a possible recycling route of upgraded BF sludge is via the existing infrastructure of briquetting. However, there are no reports on recycling of both the BF dust and upgraded BF sludge via this route. In the present study, a fine-grained and low-zinc-containing BF sludge was upgraded using the tornado process. The sludge was generated by a BF operating on $100 \%$ pellets as ferrous burden and utilizing a cyclone as primary gas-cleaning equipment. The feasibility of recycling different amounts of the low-zinc fraction of the upgraded $\mathrm{BF}$ sludge to the BF using cold-bonded briquettes was studied experimentally using a laboratory-scale BF shaft simulator.

\section{Experimental}

\section{Tornado Treatment}

Newly produced BF sludge from SSAB Oxelösund, Sweden, was used in the present study. The sludge was tornado treated aiming to dry the sludge and generate a zinc-rich and a zinc-depleted fraction. The overview of the tornado process is illustrated in Fig. 1. The sludge was discharged into a preheated airstream $\left(60^{\circ} \mathrm{C}\right)$ of high velocity, feeding the sludge tangentially into the tornado. The principle of the separation is the same as for the hydrocyclone, i.e., accelerated settling rate. The coarse and dense particles settle toward the wall and exit via the underflow, whereas the light and small particles are carried by the vortex to the overflow. In addition, the feed is subjected to mechanical effects such as attrition caused by interactions between particles. The tornado equipment has been thoroughly described by Tikka et al. [18].

Samples were taken during the trial from the feed, underflow, and overflow. Each sample was analyzed for moisture content, particle-size distribution, and chemical composition. The particle-size distribution was determined using a CILAS 1064 laser diffraction equipment. The results were evaluated using the Fraunhofer approximation. A Thermo Scientific ARL 9800 X-ray fluorescence (XRF) instrument operating a rhodium tube was used to determine the chemical composition of the sludge. A LECO CS444 combustion infrared detection analyzer was used for the determination

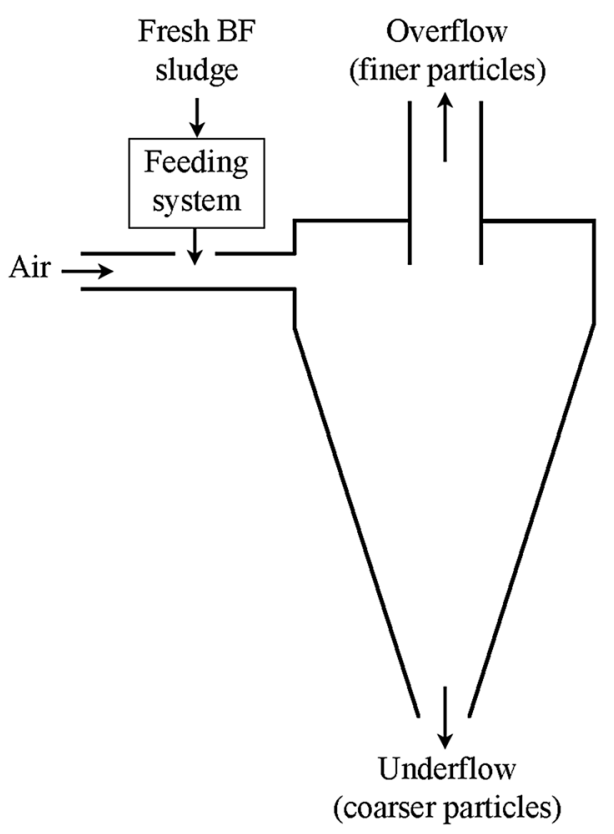

Fig. 1 Overview of the tornado process 
of carbon and sulfur. Inductively coupled plasma mass spectrometry (ICP-MS) was used to analyze the zinc content. The digestion of the sample prior to the ICP-MS analysis was achieved by microwave-assisted dissolution in a mixture of nitric acid, hydrochloric acid, and hydrofluoric acid.

\section{Briquetting and Characterization}

Three different recipes of cement-bonded briquettes were designed in the present study: (i) a recipe without added BF sludge, (ii) a recipe with $10 \mathrm{wt} \%$ upgraded BF sludge labeled B1, and (iii) a recipe with $20 \mathrm{wt} \%$ upgraded BF sludge labeled B2. The basis for the three different recipes, presented in Table 1, was a recipe applied in industrial practice at SSAB Europe. The upgraded BF sludge used was the low-zinc-containing underflow from the tornado treatment.

The particle-size distributions of the ingoing materials in the briquette recipes were determined using the CILAS 1064 laser diffraction equipment and sieving (wet or dry, depending on the coarseness of the material).

Before the briquetting, the materials were mixed in a SoRoTo 40 L-33 cement mixer with several impellers. Water, corresponding to approximately $13.5 \mathrm{wt} \%$ of the dry blend, was added to the mixture. The briquetting was accomplished using a TEKSAM VU600/6 unit. The hexagonal briquettes were approximately $7 \mathrm{~cm}$ high and $6.5 \mathrm{~cm}$ edge to edge.

After briquetting, the tumble index was determined after $24 \mathrm{~h}$ and 28 days of curing under ambient room conditions. The measurements were made in accordance with a modified version of ISO 3271; the modification was the final sieving performed using a $6.0-\mathrm{mm}$ instead of a $6.3-\mathrm{mm}$ sieve.

A Panalytical MagiX FAST XRF instrument, operating a rhodium tube, was used to determine the chemical composition of the briquettes. The carbon, sulfur, and zinc contents were determined as previously described. Contents of Fe(II) and metallic iron were determined by titration, as per ISO 9035.

The mineralogical composition of the briquettes was determined using a PANalytical Empyrean X-ray diffraction

Table 1 The three different briquette recipes

\begin{tabular}{lrlr}
\hline Material (wt\%) & Ref. & B1 & B2 \\
\hline Upgraded BF sludge & 0.0 & 10.0 & 20.0 \\
Desulfurization scrap & 36.0 & 31.4 & 26.8 \\
BOF coarse sludge & 18.0 & 15.7 & 13.4 \\
BOF fine sludge & 12.0 & 10.5 & 8.9 \\
Briquette fines & 12.0 & 10.5 & 8.9 \\
BF dust & 10.0 & 10.0 & 10.0 \\
Cement & 12.0 & 12.0 & 12.0 \\
\hline
\end{tabular}

(XRD) unit. Powder samples were measured under the following measurement conditions: $\mathrm{Cu} \mathrm{K} \alpha$ radiation, $40 \mathrm{~mA}$ electron emission current, $45 \mathrm{kV}$ accelerating voltage, measuring in the $2 \theta$ range $10-90^{\circ}$, and $0.0260^{\circ}$ step size.

An optical dilatometer made by Leitz Wetzlar, Germany was used to study the swelling behavior of the three recipes. The heating program and gas composition were designed to reproduce the conditions in the laboratory-scale BF shaft simulator described in "Laboratory Scale BF Shaft Simulation Experiments." Based on the area measurements of the silhouette of the samples, the Swelling Index, SI (\%), was calculated according to Eq. (1).

$\operatorname{SI}(\%)=\frac{\text { Change in area }}{\text { Original area }} \times 100$

\section{Laboratory-Scale BF Shaft Simulation Experiments}

The feasibility of charging briquettes incorporating upgraded $\mathrm{BF}$ sludge to the BF was tested in a laboratory-scale $\mathrm{BF}$ shaft simulator developed by LKAB. Figure 2 illustrates the experimental setup. Before each test, the height and weight of the briquette were measured. The mass loss was monitored during the experiment by suspending the equipment to a scale as illustrated by Robinson [19].

Two different programs with different heating rates and gas compositions were designed: one that simulates the descent along the wall of the BF, Fig. 3a), and one that

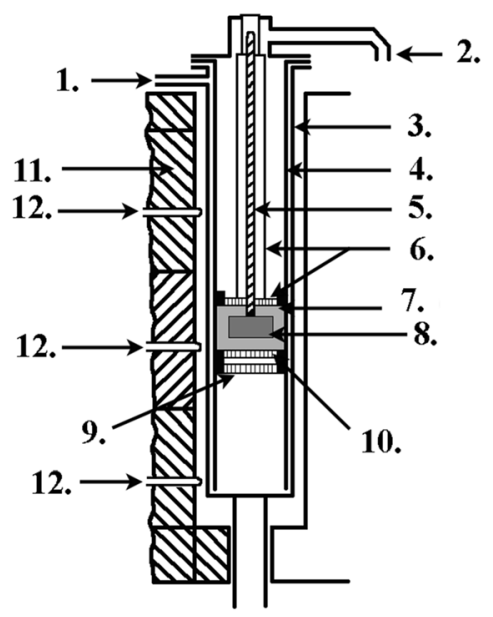

1. Opening for gas inlet 2. Opening for gas outlet

3. Outer reaction tube 4. Inner reaction tube ( $\emptyset=125 \mathrm{~mm})$

5. Thermocouple for measureing the reduction temperature

6. Loading ram with rigid perforated footplate

7. Alumina balls 8. Sample 9. Perforated support

10. Removable perforated plate 11. Furnace wall

12. Furnace wall thermocouples: upper, medial and lower

Fig. 2 Experimental setup of the laboratory-scale BF shaft simulator 


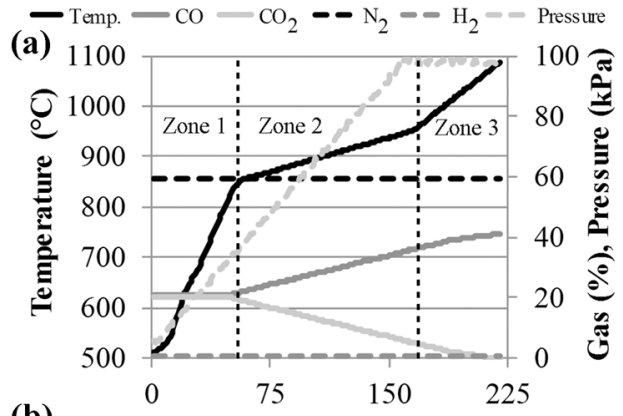

(b)

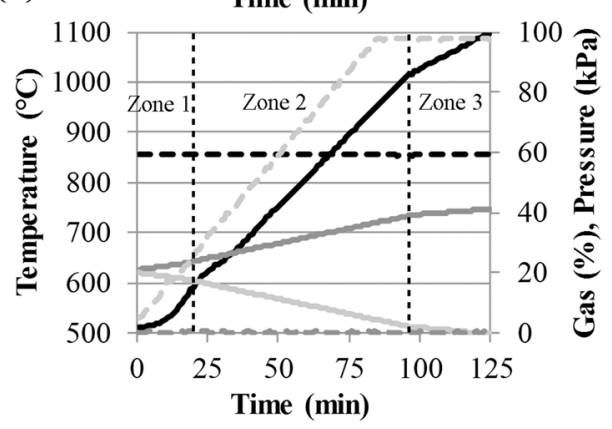

Fig. 3 Temperature, mechanical pressure, and gas profiles of the a wall program and $\mathbf{b}$ center program. The mechanical pressures and the gas compositions are given in the right $y$-axes

simulates the descent in the center of the BF, Fig. 3b). During the experiments, the gas mixture was added at a constant flow rate of $50 \mathrm{Nl} / \mathrm{min}$. Furthermore, the heating up to $500{ }^{\circ} \mathrm{C}$ was made in $\mathrm{N}_{2}$ atmosphere in both programs. The pressure applied by the loading ram, as seen in Fig. 3, was a mechanical pressure. Thus, the total pressure of the gas phase was not altered.

The dashed vertical lines in Fig. 3, marked in both the wall and center programs, intersect the temperature curves where a change in heating rate occurs. The three different regions of each program, marked by these two lines, are labeled as zone 1 , zone 2 , and zone 3 . In addition to running all three briquettes through the whole wall and center programs, the reference and B2 briquettes were run in interrupted tests. The wall program was interrupted at the end of the first and second zones, respectively. The center program, having a more rapid heating cycle, was interrupted at the end of the second zone and middle part of the third zone, respectively. The reference and B2 briquettes were chosen for the interrupted tests as these two represents the two boundary cases in terms of the addition of upgraded BF sludge.

After the reduction procedures, the briquettes were cooled in nitrogen atmosphere. The briquettes were weighed, and the dimensions after reduction were measured. The chemical and mineralogical compositions were determined using the same approach as for the nonreduced briquettes. In addition, selected briquettes were analyzed using scanning electron microscopy (SEM) together with energy dispersive X-ray

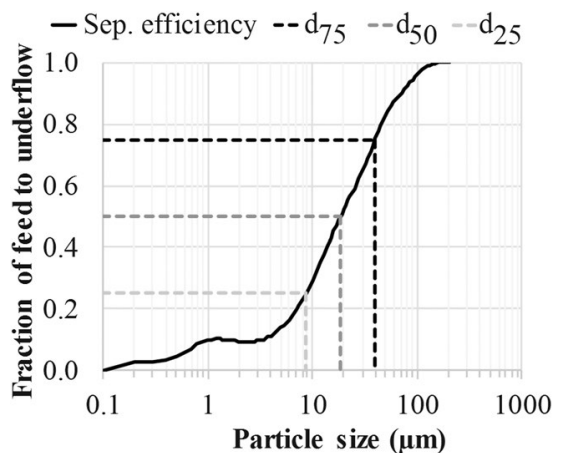

Fig. 4 Separation efficiency curve for the tornado

spectroscopy (EDS). For this purpose, a Gemini Zeiss Merlin microscope incorporating an Oxford EDS detector was used.

\section{Results and Discussion}

\section{Tornado Treatment}

Figure 4 illustrates the separation efficiency curve of the tornado experiment. The curve relates the weight fraction of each particle size in the feed that reports to the underflow. The dashed lines represent the $\mathrm{d}_{75}, \mathrm{~d}_{50}$, and $\mathrm{d}_{25}$ determined to be 40,19 , and $9 \mu \mathrm{m}$, respectively. The $\mathrm{d}_{75}$ represents the particle size where $75 \%$ of the particles of this particular particle size in the feed report to the underflow, and the $\mathrm{d}_{50}$ and $d_{25}$ values are determined analogously for 50 and $25 \%$, respectively. In order to quantitate the sharpness of separation the imperfection, I, was calculated to be 0.84 according to Eq. (2). During hydrocycloning of BF sludge, values of I have been determined to be 0.35 and 0.29 for one and two-stage hydrocycloning, respectively [6]. Considering that dry cyclones are suitable in operation down to $10 \mu \mathrm{m}$ [20], the utilization of the tornado is feasible. The difference in the separation efficiencies between the hydrocyclone and tornado can be attributed to (i) possible re-entrainment due to the high velocity of the tornado inlet stream [20] and/or (ii) the fact that the hydrocyclone dimensions were optimized for the sludge [6], whereas the tornado used in the present study had limited means for control of dimensional parameters.

$I=\frac{d_{75}-d_{25}}{2 d_{50}}$

The chemical compositions of the original sludge and the fractions reporting to the overflow and underflow are presented in Table 2. Also, the moisture contents prior to 
Table 2 Chemical compositions of dried materials and moisture contents before drying (wt\%)

\begin{tabular}{llllc}
\hline Material & Fe & C & Zn & Moisture \\
\hline Feed & 35.6 & 23.6 & 0.40 & 39.9 \\
Underflow & 38.1 & 27.1 & 0.24 & 1.7 \\
Overflow & 29.6 & 19.5 & 2.18 & 1.8
\end{tabular}

drying and analyzing the materials are presented. The given values are the average values of three to six samples of each material stream taken during the process.

During the upgrading of the sludge, $31 \%$ of the total solids reported to the underflow. Hydrocycloning of BF sludge of similar particle-size distribution yielded $67 \%$ solids recovery in the underflow [6], which reflects the difference in separation efficiencies. The distribution of iron, carbon, and zinc to the underflow was estimated based on a back-calculated feed. The distributions of iron, carbon, and zinc to the underflow were calculated to be 37,39 , and $5 \%$, respectively. The material balances of iron and carbon over the tornado process were considered acceptable, deviating less than $10 \%$. However, the outgoing zinc was considerably higher compared to the zinc in the feed. The improper zinc balance was due to the high zinc content of the overflow. No apparent reason for this high value, which was an average of three samples, could be found. However, the role of the tornado process is to introduce an outlet for zinc exiting from the recycling system. Therefore, as the zinc analysis of the underflow was lower than that of the feed, the results were considered satisfactory. Furthermore, calculating a new distribution of zinc to the underflow based on the zinc analyses of the underflow and feed material suggested that $19 \%$ of the total zinc content reported to the underflow. Thus, even with this more conservative value, $81 \%$ of the total zinc content can be removed.

Although the hydrocyclone has better sharpness of separation, the simultaneous drying and upgrading of the sludge are advantageous as the fine particle-size distribution of the sludge makes the sludge difficult to dewater. Therefore, the effect of incorporating the dry low-zinc fraction of the BF sludge into cold-bonded briquettes is of special interest for this study. The characteristics of the briquettes have to meet the demands on agglomerates charged to the top of the BF.

\section{Briquetting and Characterization}

\section{Chemical and Mineralogical Compositions}

The chemical compositions of the briquettes are presented in Table 3. The total iron content is higher when using upgraded BF sludge in the blend. However, the addition of
Table 3 Chemical compositions of the three briquettes

\begin{tabular}{lccc}
\hline Element & Ref. $(\%)$ & B1 (\%) & B2 (\%) \\
\hline $\mathrm{Fe}_{\text {tot }}$ & 50.6 & 51.5 & 52.8 \\
$\mathrm{Fe}_{\text {metallic }}$ & 29.8 & 22.4 & 19.8 \\
$\mathrm{Fe}(\mathrm{II})$ & 4.8 & 5.1 & 5.3 \\
Calculated Fe(III) & 16.0 & 24.0 & 27.7 \\
$\mathrm{C}$ & 7.7 & 10.8 & 12.8 \\
$\mathrm{CaO}$ & 19.9 & 17.9 & 16.5 \\
$\mathrm{SiO}_{2}$ & 4.6 & 5.0 & 5.1 \\
$\mathrm{MgO}$ & 2.0 & 2.0 & 1.9 \\
$\mathrm{Al}_{2} \mathrm{O}_{3}$ & 1.6 & 1.8 & 1.7 \\
$\mathrm{Zn}$ & 0.039 & 0.098 & 0.141 \\
\hline
\end{tabular}

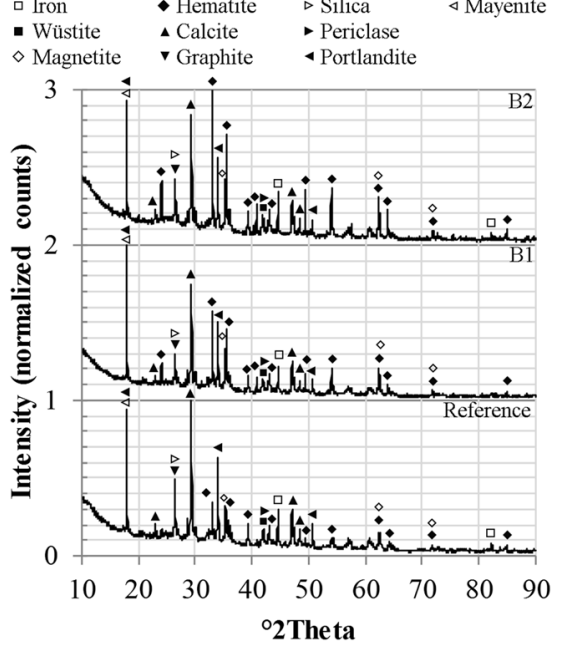

Fig. 5 Diffractograms of the nonreduced briquettes

upgraded BF sludge, replacing the other constituents of the recipe, generated a noticeable lower metallic iron content and calcium content. Also, increasing additions of upgraded $\mathrm{BF}$ sludge resulted in noticeably higher $\mathrm{Fe}(\mathrm{III})$, carbon, and zinc contents. The $\mathrm{Fe}(\mathrm{III})$ content was calculated based on the total iron content determined by the XRF and the $\mathrm{Fe}(\mathrm{II})$ and metallic iron contents determined by the titration analysis.

The diffractograms of the three briquettes are presented in Fig. 5. The detected phases were iron $(\mathrm{Fe})$, wüstite $(\mathrm{FeO})$, magnetite $\left(\mathrm{Fe}_{3} \mathrm{O}_{4}\right)$, hematite $\left(\mathrm{Fe}_{2} \mathrm{O}_{3}\right)$, calcite $\left(\mathrm{CaCO}_{3}\right)$, graphite $(\mathrm{C})$, silica $\left(\mathrm{SiO}_{2}\right)$, periclase $(\mathrm{MgO})$, portlandite $\left(\mathrm{Ca}(\mathrm{OH})_{2}\right)$ and mayenite $\left(\mathrm{Ca}_{12} \mathrm{Al}_{14} \mathrm{O}_{33}\right)$. These phases were seen in all briquettes, i.e., no qualitative difference was observed. However, distinguished differences in the number of hematite peaks and the relative intensities of these peaks were observed. The relative intensity refers to the relative amount of counts registered for a peak as compared to the highest peak in the diffractogram. Increasing amounts of 
added BF sludge corresponded to increasing relative intensities of the highest peak distinctive for the diffractogram of hematite detected at $33.1^{\circ} 2 \theta$.

The difference in the chemical composition of the three briquettes reflects the substitution of desulfurization scrap, BOF coarse sludge, BOF fine sludge, and briquette fines with the upgraded BF sludge. The upgraded sludge carries more $\mathrm{Fe}$ (III) and carbon and less calcium than the other materials. Based on the higher relative intensities of hematite and the larger number of hematite peaks observed in the XRD, the increased Fe(III) was found as hematite. The additional $\mathrm{Fe}$ (III) from the BF sludge requires more oxygen to be removed in order to reach a full reduction of the iron oxides. However, the net effect of the BF sludge additions is an increased carbon to oxygen molar ratio. After deducting the carbon present in calcite, the carbon to oxygen molar ratio in the reference, $\mathrm{B} 1$, and $\mathrm{B} 2$ briquette was calculated to $0.92,1.05$ and 1.14 , respectively. Thus, the addition of upgraded BF sludge makes the agglomerate, theoretically, self-reducible and provides additional carbon that can participate in reactions in the BF. Furthermore, increasing $\mathrm{C} / \mathrm{O}$ molar ratios have been shown to facilitate improved reduction degrees [21-23] and reduction rates [22] in selfreducing agglomerates.

\section{Tumble Index and Swelling}

The cold strength of the cold-bonded agglomerates is essential to consider when determining if the agglomerates can sustain the conditions prevailing inside the BF. Inadequate cold strength leads to breakage during material handling and charging, which results in increased dust formation from the BF. Furthermore, low cold strength may cause the agglomerates to disintegrate and impair the gas permeability in the furnace. The tumble indices after $24 \mathrm{~h}$ of curing were determined to be 42,47 , and $48 \%$ for the reference, B1, and B2 briquettes, respectively. These results suggest that a higher strength after $24 \mathrm{~h}$ of curing can be achieved by adding the upgraded BF sludge. After 28 days of curing, the tumble indices were determined to 78,84 , and $81 \%$ for the reference, B1, and B2 briquettes, respectively.

The compressive strength of the cold-bonded briquettes has been shown to increase consistently with the decreasing $d_{50}$ [24]. In the present study, the $d_{50}$ values were calculated to be 255,185 , and $145 \mu \mathrm{m}$ for the material blends of the reference, B1, and B2 briquette, respectively. Thus, no consistent increase in strength with the decreasing $\mathrm{d}_{50}$ was observed after 28 days of curing. Other factors affecting the strength of cold-bonded briquettes are the zinc and carbon contents. Zinc compounds slow the cement setting time by forming a protective layer on cement grains [25], and the hydrophobic nature of carbon disturbs the wetting and induce an effect of set retardation in the cement [26]. These two factors would contribute to a lower tumbling index with the increasing amount of upgraded BF sludge added as the sludge additions resulted in higher zinc and carbon contents, Table 3 . The collective effect of lower $d_{50}$ values and higher contents of zinc and carbon was on average the higher tumbling indices for the briquettes with the addition of the upgraded BF sludge. Furthermore, the strength requirement for top-charging of cold-bonded briquettes in the $\mathrm{BF}$ is $60 \%$ [27]. Thus, the cold strength of the BF sludge-containing briquettes after curing is satisfactory.

Swelling during reduction is another important phenomenon to consider when charging agglomerates in the top of the BF. Abnormal, or catastrophic, swelling upon heating and reduction significantly reduces the strength of the agglomerates and may ultimately have a negative effect on the BF operation. The maximum recorded swelling indices were observed between 944 and $1009^{\circ} \mathrm{C}$ and were determined to be 18,27 , and $24 \%$ for the reference, B1, and B2 briquettes, respectively.

Increased coke contents of the cement-bonded briquettes have been shown to increase the swelling [28, 29]. Thus, considering the chemical compositions of the briquettes, Table 3, the coke fines present in the upgraded BF sludge should increase the swelling tendencies of the $\mathrm{B} 1$ and $\mathrm{B} 2$ briquettes. Furthermore, the presence of $\mathrm{CaO}$ in the wüstite structure has been shown to favor iron whisker formation during reduction, and therefore swelling tendencies increase [30]. Although the briquettes of the present study had different calcium contents, Table 3, the effect on the swelling is ambiguous as the documented effect differs between studies [31-33]; i.e., the $\mathrm{CaO}$ content in wüstite determines the effect on swelling, not the overall $\mathrm{CaO}$ content in the agglomerate. The same ambiguity concerns the effect of the particle-size distribution of the agglomerate recipe. Fredriksson et al. [34] observed that increasing the grain size of the ingoing material in cement-bonded pellets reduced the isothermal swelling of the agglomerate, while Singh et al. [29] showed a clear increase in the swelling of coldbonded briquettes with the increasing $\mathrm{d}_{50}$. Considering this, the collective effect of the differences in chemical composition and particle-size distribution on the swelling index cannot be determined. Nonetheless, swelling up to $20 \%$ is generally accepted as normal, and values higher than this is referred to as abnormal or catastrophic [35]. Furthermore, Seaton et al. [36] referred to swelling indices between 20 and $27 \%$ as acceptable and normal. Also, Nascimento et al. [37] and Abdel Halim et al. [38] proposed that swelling indices around $20 \%$ are normal, whereas much higher values are considered catastrophic. These much higher indices were exemplified by studies reporting swelling indices exceeding $400 \%$ [38]. In contrast to these values, the higher swelling indices during reduction accompanied by the addition of upgraded BF sludge in the present study were modest. Thus, 
as the swelling indices of the present study were around $20 \%$, the swelling was considered acceptable.

Based on the above, the addition of upgraded BF sludge does not compromise the characteristics of the reference briquette with regards to the cold strength and swelling. Furthermore, the qualitative mineralogical composition was identical, and the chemical composition suggested possible benefits in terms of the higher carbon-to-oxygen molar ratio. Therefore, simulating the BF in laboratory scale is of special interest as a first step to study the feasibility of recycling the agglomerates containing the upgraded BF sludge via top-charging.

\section{Laboratory-Scale BF Shaft Simulation Experiments}

\section{Reactions During the Wall Program}

Figure 6 illustrates the mass loss curves after $500{ }^{\circ} \mathrm{C}$ of the three briquettes going through the wall program in the laboratory-scale BF shaft simulation experiments. Furthermore, the mass loss and temperatures of the interrupted tests are presented as points in the figure. The three briquettes show similar mass loss profiles, Fig. 6. The main difference between the briquettes is the final mass loss, which reflects the available carbon and oxygen to be removed, Table 3. No apparent explanation was found for the difference in mass loss after the second zone of the interrupted tests and the full program. However, this difference in mass loss was acknowledged. The events and reactions corresponding to the mass loss in the different zones are accounted for in the text below.

As the briquettes were charged without predrying, the evaporation of free and crystal-bound water was assumed to occur prior to reaching $500{ }^{\circ} \mathrm{C}$. In addition, the dehydration of portlandite to lime, Eq. (3), was assumed to occur before introducing the reducing gases at $500{ }^{\circ} \mathrm{C}$. This assumption was based on the experiments of Alonso and Fernandez [39] who showed that the dehydration of portlandite occurs at temperatures lower than $450{ }^{\circ} \mathrm{C}$ in nitrogen atmosphere.

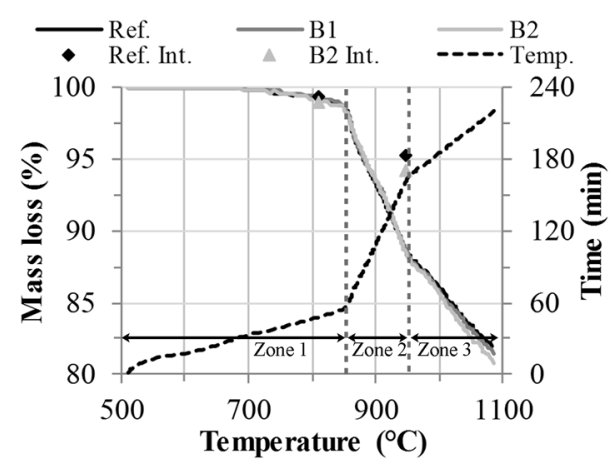

Fig. 6 The mass losses recorded in the wall program. The interrupted tests are labeled Int
$\mathrm{Ca}(\mathrm{OH})_{2} \leftrightarrow \mathrm{CaO}+\mathrm{H}_{2} \mathrm{O}$

The diffractograms of the $\mathrm{B} 2$ briquettes after the interrupted and final wall program are presented in Fig. 7. The B2 briquette was chosen to be presented as this recipe had the highest average oxidation state of iron. No qualitative differences were observed when comparing the mineralogy of the reference and B2 briquettes subjected to the interrupted tests. However, the relative intensities of the peaks corresponding to the iron oxide phases were higher in the B2 briquette.

According to Fig. 7, hematite was not detected after the first zone of the wall program suggesting that hematite was reduced to magnetite, Eq. (4). Furthermore, the relative intensities of the shared peaks of wüstite and periclase after the first zone suggest that reduction of magnetite to wüstite, Eq. (5), started as well. Both Eqs. (4) and (5) can be written with hydrogen gas as reducing agent since it was included in the gas mix, Fig. 3.

$3 \mathrm{Fe}_{2} \mathrm{O}_{3}+\mathrm{CO} \leftrightarrow 2 \mathrm{Fe}_{3} \mathrm{O}_{4}+\mathrm{CO}_{2}$

$\mathrm{Fe}_{3} \mathrm{O}_{4}+\mathrm{CO} \leftrightarrow 3 \mathrm{FeO}+\mathrm{CO}_{2}$

The wt $\%$ of the valences of iron in the reference and B2 briquettes after the interrupted and full wall programs are presented in Fig. 8. After the first zone, reaching $850{ }^{\circ} \mathrm{C}$, both the reference and $\mathrm{B} 2$ briquette were analyzed for lower $\mathrm{Fe}(\mathrm{III})$ and higher $\mathrm{Fe}(\mathrm{II})$ contents. This is consistent with the results of the XRD. Furthermore, the metallic iron content in the reference briquette was lower after the first zone compared to the nonreduced briquette, Fig. 8. This suggests that reorganization of the oxygen between the iron phases occurred. This phenomenon has been observed previously and was attributed to solid diffusion of oxygen from higher oxidation states to lower ones [40].

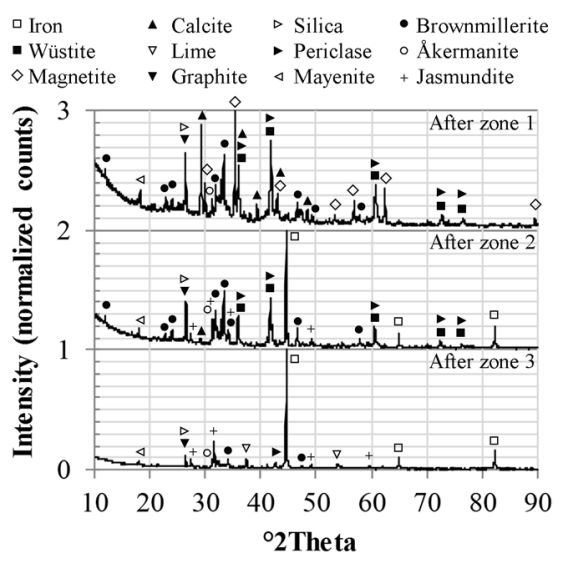

Fig. 7 Diffractograms of the B2 briquette subjected to the wall program 
The propagation of the reduction is consistent with the $\mathrm{Fe}-\mathrm{C}-\mathrm{O}$ diagram, Fig. 9, considering the conditions of the wall program after the first zone at $850{ }^{\circ} \mathrm{C}$. The $\mathrm{Fe}-\mathrm{C}-\mathrm{O}$ diagram was reproduced using FactSage 7.2 utilizing the FactPS database and calculating on a total pressure of $1 \mathrm{~atm}$. The relative intensities of the magnetite peaks in the diffractogram of the reference briquette after the first zone of the wall program were considerably less than those of the B2 briquette. Thus, although the $\mathrm{C} / \mathrm{O}$ molar ratio was higher for the $\mathrm{B} 2$ briquette, the overall reduction had not progressed further. However, in accordance with the results of Shivaramakrishna et al. [22], the overall reduction rate was higher in the $\mathrm{B} 2$ briquette. The rates at which the oxygen bound to iron decreased per minute in the first zone were calculated to be 0.011 and $0.072 \% \mathrm{O} / \mathrm{min}$ for the reference and $\mathrm{B} 2$ briquette, respectively. Thus, the difference in reduction after the first zone was attributed to a higher original content of $\mathrm{Fe}(\mathrm{III})$ in the $\mathrm{B} 2$ briquette.

Considering the above, the mass loss recorded in the first zone corresponded to the net removal of oxygen from the iron oxides.

Magnetite was not found in the XRD measurements of the briquettes after the second zone. These results suggest

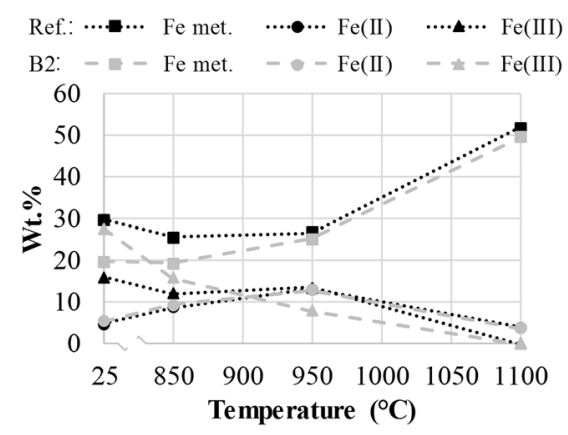

Fig. 8 Weight percentage of valences of iron analyzed in the wall program

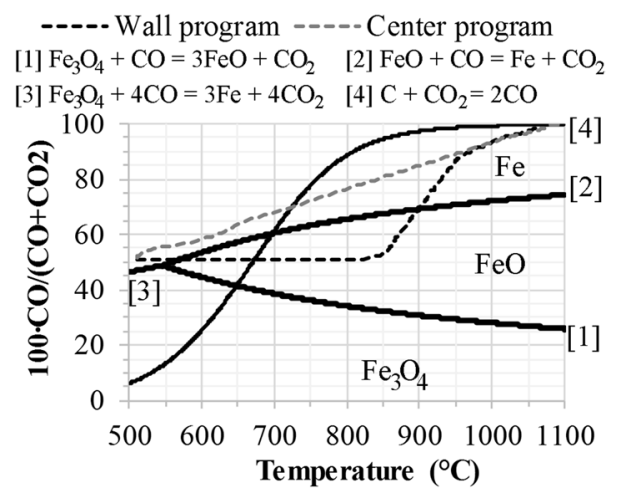

Fig. 9 Fe-C-O diagram including the conditions of the wall and center programs that the reaction in Eq. (5) was completed. However, as shown in Fig. 8, Fe(III) was still present after the second zone. This ferric iron may be present in, e.g., brownmillerite $\left(\mathrm{Ca}_{2}(\mathrm{Al}, \mathrm{Fe})_{2} \mathrm{O}_{5}\right)$ or wüstite. The $\mathrm{Fe}(\mathrm{III})$ content in wüstite can range from 7.5 to $29.9 \mathrm{wt} \%$ of the total mass of wüstite [41]. Nonetheless, as these samples were not studied with the SEM-EDS, the XRD suggests that the reaction in Eq. (5) propagated long enough to leave magnetite below the detection limit of the XRD equipment.

The relative intensities of wüstite and iron in the diffractogram of the B2 briquette, Fig. 7, after the second zone, compared to after the first zone, suggest that the reaction in Eq. (6) started. This is consistent with the conditions of the wall program at $950{ }^{\circ} \mathrm{C}$ depicted in the $\mathrm{Fe}-\mathrm{C}-\mathrm{O}$ diagram, Fig. 9. Also, the higher reduction rate given in $\% \mathrm{O} / \mathrm{min}$ of the $\mathrm{B} 2$ briquette under the prolonged time of the second zone resulted in less oxygen bound to the iron phases in the B2 briquette as compared to the reference briquette, Fig. 8 . Furthermore, based on the change in the relative intensity of calcite, the calcination reaction, Eq. (7), had started. Thus, the continuation of the reduction of the iron oxides and the calcination corresponded to the mass loss observed in the second zone, Fig. 6.

$\mathrm{FeO}+\mathrm{CO} \leftrightarrow \mathrm{Fe}+\mathrm{CO}_{2}$

$\mathrm{CaCO}_{3} \leftrightarrow \mathrm{CaO}+\mathrm{CO}_{2}$

No iron oxides were detected after the third zone of the wall program, ending at $1100^{\circ} \mathrm{C}$, Fig. 7 , suggesting that the reduction of wüstite to iron was completed. However, the analyzed valences of iron as shown in Fig. 8 suggest that $\mathrm{Fe}$ (II) was present in both the reference and $\mathrm{B} 2$ briquette after the full wall program.

The SEM-EDS study was performed on the reference, $\mathrm{B} 1$, and $\mathrm{B} 2$ briquettes that had gone through the full wall program. Iron was detected as smaller particles in the single digit micrometer size range as well as larger particles as shown by the white particles in Fig. 10. Iron particles

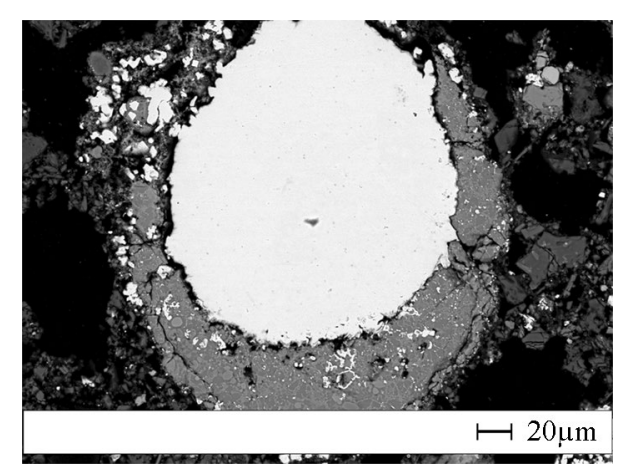

Fig. 10 Micrograph recorded using an angle-selective backscatter detector showing an iron particle surrounded by an oxide layer 
of $100 \mu \mathrm{m}$ and larger were generally detected with a surrounding layer of oxides. The EDS spectrums suggested that these layers were comprised of a calcium silicate and solid solutions of iron and magnesium oxide. The solid solutions of $(\mathrm{Fe}, \mathrm{Mg}) \mathrm{O}$ explains the $\mathrm{Fe}(\mathrm{II})$ content observed after the full wall program, Fig. 8. Thus, the reaction in Eq. (6) was completed in neither the reference, B1 nor the B2 briquette.

Calcite was not detected after the third zone. Furthermore, the carbon contents of the reference briquette were $6.4 \%$ after the second zone and $2.7 \%$ after the third zone. The corresponding values for the B2 briquette were 9.9\% after the second zone and $6.4 \%$ after the third zone. Thus, the mass loss during the third zone corresponded to the completion of the calcination reaction, the continuation of the reduction of wüstite to iron, and the utilization of the carbon in the briquettes.

Iron oxides reaching the lower shaft will be partly reduced by direct reduction. Thus, deciding the degree of reduction (DoR) in a position representing the lower shaft is of great importance. In the present paper, the DoR based on oxygen bound to iron was used. The DoR was calculated according to Eq. (8).

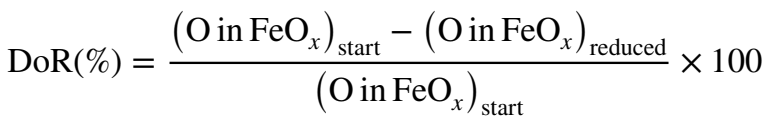

The DoR values after the full wall program were calculated to be 86,65 , and $92 \%$ for the reference, B1, and B2 briquettes, respectively. The oxygen bound to the iron of the B2 briquette suggests that adding $20 \mathrm{wt} \%$ of upgraded BF sludge leaves the briquette effectively reduced. On the other hand, the DoR of the B1 briquette suggested that a lower addition of upgraded BF sludge influenced the reducibility negatively.

\section{Reactions During the Center Program}

Similar to the wall program, the evaporation of free and crystal-bound water as well as the dehydration of portlandite to lime was assumed to occur prior to reaching $500{ }^{\circ} \mathrm{C}$. The propagation of the reduction in the center program was studied by running XRD on the briquettes subjected to the interrupted tests. After reaching $1000{ }^{\circ} \mathrm{C}$ at the end of the second zone, Fig. 11, neither hematite nor magnetite was detected in the reference and $\mathrm{B} 2$ briquettes suggesting that the reduction to wüstite was completed. Furthermore, based on the relative intensities of the wüstite and iron peaks, the reduction of wüstite to iron had started. This is consistent with the conditions of the center program at $1000{ }^{\circ} \mathrm{C}$ in the $\mathrm{Fe}-\mathrm{C}-\mathrm{O}$ diagram in Fig. 9. Also, the calcination reaction was finished as calcite was not detected in the briquettes. Thus, the mass loss during the first and second zone of the

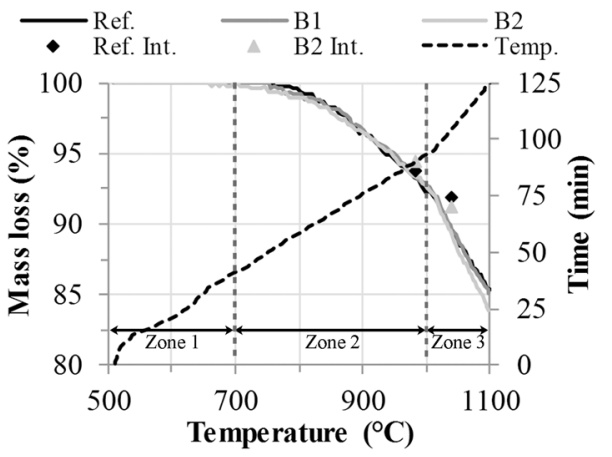

Fig. 11 The mass losses recorded in the center program. The interrupted tests are labeled Int

Table 4 Weight percentages of the valences of iron after the full center program

\begin{tabular}{lllll}
\hline Briq & Fe met & Fe(II) & Fe(III) & DoR \\
\hline Ref & 49.3 & 3.2 & 0.5 & 86 \\
B1 & 50.4 & 2.6 & 0.0 & 93 \\
B2 & 39.2 & 5.9 & 3.5 & 74 \\
\hline
\end{tabular}

center program, Fig. 11, was made up of the reduction and calcination reactions.

The reduction of wüstite to iron was incomplete in both the reference and the $\mathrm{B} 2$ briquette reaching halfway through the third zone at $1050{ }^{\circ} \mathrm{C}$. Wüstite was not detected in the reference, $\mathrm{B} 1$, or $\mathrm{B} 2$ briquette after the complete center program suggesting complete reduction. However, the wt $\%$ values of the valences of iron in the briquettes, Table 4, suggest that wüstite or solid solutions of $(\mathrm{Fe}, \mathrm{Mg}) \mathrm{O}$ are present. The respective carbon contents of the reference briquette were $6.8 \%$ after the second zone and $4.1 \%$ after the third zone. The corresponding values for the B2 briquette were $11.4 \%$ after the second and $7.8 \%$ after the third zone. Thus, the mass loss, going from the end of the second to the end of the third zone, was composed of the continuation of the reduction and the utilization of carbon.

The DoR of the reference briquette was determined to $86 \%$ after both the wall and center programs. The B1 briquette appears to be more reduced after the center program (DoR of 93\%) compared to that after the wall program (DoR of $65 \%)$. Considering the more rapid heating cycle in the center program, the results of the B1 briquette are counterintuitive, especially as the B2 briquette was satisfactorily reduced after the wall program. This discrepancy may be attributed to the XRF analysis of the total iron content in the $\mathrm{B} 1$ briquette after the full wall program. The value was noticeably higher than all other iron analyses. The effect of this high value was an overestimation of the calculated $\mathrm{Fe}(\mathrm{III})$ content and therefore a high value of oxygen bound 
to iron after the full wall program. Considering this, the DoR of the $\mathrm{B} 1$ briquette after the wall program may be underestimated and the briquette could be satisfactorily reduced after both programs.

The B2 briquette was considerably less reduced after the shorter center program (DoR of 74\%) compared to the longer wall program (DoR of 92\%). The average reduction rates during the center program were calculated to be 0.057 and $0.081 \% \mathrm{O} / \mathrm{min}$ for the reference and $\mathrm{B} 2$ briquette, respectively. Therefore, the seemingly poor reducibility of the $\mathrm{B} 2$ briquette can be attributed to the insufficient time compared to what was required in order to reduce the additional amount of iron oxides provided by the upgraded BF sludge. In comparison with the DoR of the reference briquette, the conclusion is that adding up to $20 \mathrm{wt} \%$ of upgraded BF sludge leaves the briquette properly reduced during the descent under conditions of the wall program. However, $10 \mathrm{wt} \%$ was the maximum amount of addition of the upgraded BF sludge, tested in the present study, which facilitates proper reducibility if the descent occurs under the conditions of the center program.

\section{Observations on Strength and Swelling}

In contrast to the results of the optical dilatometer, the briquettes did not swell in the laboratory-scale BF shaft experiments. The briquettes reaching the end of the first, second, and third zones in the wall program had average heights of 97,88 , and $86 \%$ of the initial height, respectively. In the center program, the average heights of the briquettes after the second, middle of the third, and end of the third zone were 95,89 , and $83 \%$ of the initial height, respectively.

The surfaces of the briquettes were smooth in all directions for every experiment, which suggests that the surrounding load, applied by the alumina balls and stamp countered the tendency to swell. The results are in line with previous studies where the tendency to swell was shown to be diminished by the surrounding load [28, 42].

The briquettes with the addition of upgraded BF sludge were consistently less disintegrated and were harder to break. These visual observations are in agreement with the tumble indices.

\section{Considerations for the Full-Scale BF}

Considering the promising results of the laboratory-scale BF shaft simulator, three questions rose: (i) how does the addition of the upgraded BF sludge in the briquette change the chemical composition of the slag and the slag volume? (ii) what is the increase in the zinc load? and (iii) is the laboratory-scale simulator a valid approximation of the BF shaft?

The first question was addressed by means of a previously developed mass balancing model described by
Hooey et al. [43]. Based on the differences in the chemical compositions of the three briquettes used in the present study, the slag chemistry and slag volume in the BF were calculated. By maintaining a constant hot metal production and slag basicity in the calculations, the differences in the slag chemistry and volume were found to be acceptable suggesting that the briquettes are feasible from a slag perspective.

The second question was addressed based on the difference in zinc contents, Table 3 , and a feasible addition rate of cold-bonded briquettes. With a rate of addition at $100 \mathrm{~kg}$ of briquettes per ton hot metal in the $\mathrm{BF}$, the addition of 10 or $20 \mathrm{wt} \%$ of upgraded BF sludge would increase the zinc load in the furnace by 59 or 102 grams per ton hot metal, respectively. However, at these rates of additions of upgraded BF sludge, the operation with these briquettes requires only shorter time periods to cover the annual generation of $\mathrm{BF}$ sludge. Considering the operation at SSAB, Oxelösund, where the sludge of the present study was sampled, the required rate of addition to the briquettes in order to recycle the sludge upgraded using the tornado would be $3.7 \mathrm{wt} \%$.

The third question was addressed by referring to the literature reporting both the use of laboratory-scale BF simulators and the subsequent scaling up of their experiments. In a comparison of the results from a laboratory-scale $\mathrm{BF}$ simulation experiment and basket samples from the LKAB $\mathrm{EBF}$, Sterneland et al. concluded that the reduction was similar in both cases [44]. In addition, the EBF represents the conditions in the commercial BF operation well [45]. This indirectly suggests that the laboratory-scale experiments offer a feasible simulation of the full-scale BF. Furthermore, Yokoyama et al. [46] utilized a laboratory-scale BF shaft simulator with a heating and gas profile similar to the wall program of the present paper. The carbon consumption ratio of reactive coke agglomerates from the interrupted laboratory tests was compared to that of probe samples of baskets in full-scale operation, finding that the shaft simulator can be used in order to simulate the shaft of the BF [46]. Thus, the laboratory-scale BF shaft simulation experiments are a valid approximation of the full-scale operation, which support the findings of the present paper, to be confirmed in experiments in a larger scale. Based on the results, the briquettes were decided to be included as basket samples in a future campaign in the LKAB EBF.

\section{Conclusion}

In the present paper, the upgrading and recycling of a finegrained and low-zinc-containing BF sludge were studied. The upgrading, referring to the removal of zinc, was studied using the tornado process concluding that: 
- The equipment can be used to separate $81 \%$ of the total zinc content leaving a fraction low in zinc carrying of 37,39 , and $31 \%$ of the total iron, carbon, and solids, respectively.

- The equipment effectively dries the sludge, generating an overflow and underflow with low moisture contents.

The feasibility of recycling the low-zinc fraction of the sludge from the tornado process was studied experimentally utilizing a laboratory-scale BF shaft simulator. The low-zinc fraction was incorporated into cold-bonded briquettes in amounts of 10 and $20 \mathrm{wt} \%$. By comparing the two different briquettes to a reference recipe, without any BF sludge, the following observations were concluded:

- The briquettes containing upgraded BF sludge showed higher quality in terms of tumbling strength and lower levels of disintegration during reduction under load.

- Addition of up to $20 \mathrm{wt} \%$ of the upgraded BF sludge did not compromise the reducibility of the briquette in an experiment simulating the descent along the wall of the furnace.

- Addition of $10 \mathrm{wt} \%$ of upgraded BF sludge was the maximum tested amount that left the briquette satisfactorily reduced after an experiment simulating a rapid descent in the center of the BF.

The results were considered promising, and a decision to try the same briquettes as basket samples in a future campaign in the LKAB EBF was made.

Acknowledgements The authors wish to thank the Swedish Energy Agency and the research program Iron and Steel Industry Energy Use (JoSEn) for financial support. The authors would also like to thank the project committee members of JK21069 Smart Recycling of Residues from Ore Based Steelmaking for their feedback. The project was conducted within CAMM - Center of Advanced Mining and Metallurgy at the Luleå University of Technology.

\section{Compliance with Ethical Standards}

Conflict of interest The corresponding author states that there are no conflicts of interest.

Open Access This article is distributed under the terms of the Creative Commons Attribution 4.0 International License (http://creativeco mmons.org/licenses/by/4.0/), which permits unrestricted use, distribution, and reproduction in any medium, provided you give appropriate credit to the original author(s) and the source, provide a link to the Creative Commons license, and indicate if changes were made.

\section{References}

1. Senk D, Gudenau HW, Geimer S, Gorbunova E (2006) Dust injection in iron and steel metallurgy. ISIJ Int 46:1745-1751. https:// doi.org/10.2355/isijinternational.46.1745
2. Das B, Prakash S, Reddy PSR, Misra VN (2007) An overview of utilization of slag and sludge from steel industries. Resour Conserv Recycl 50:40-57. https://doi.org/10.1016/j.resco nrec.2006.05.008

3. Topkaya Y, Sevinç N, Günaydın A (2004) Slag treatment at Kardemir integrated iron and steel works. Int J Miner Process 74:31-39. https://doi.org/10.1016/j.minpro.2003.08.005

4. Wedholm A (2016) Briquetting - taking advantage of fine-grained residues in a sustainable manner. In: Proceedings of SCANMET V 5 th international conference on process development in iron and steelmaking

5. Geerdes M, Chaigneau R, Kurunov I, Lingiardi O, Ricketts J (2015) Modern blast furnace ironmaking: an Introduction. IOS Press, Amsterdam. https://doi.org/10.3233/978-1-61499-499-2-i

6. Andersson A, Ahmed H, Rosenkranz J, Samuelsson C, Björkman B (2017) Characterization and upgrading of a low zinc-containing and fine blast furnace sludge-a multi-objective analysis. ISIJ Int 57:262-271. https://doi.org/10.2355/isijinternational.ISIJI NT-2016-512

7. Heijwegen CP, Kat W (1983) Zinc-bearing waste products in the iron and steel industry; their composition and possible hydrometallurgic processing methods. World Steel Metalwork 5:26-34

8. Butterworth P, Linsley K, Aumonier J (1996) Hydrocyclone treatment of blast furnace slurry within British steel. Rev Métall 93:807-815. https://doi.org/10.1051/metal/199693060807

9. Heijwegen CP, Kat W (1984) Beneficiation of blast furnace sludge. World steel metalwork. Export Manag 26:35-39.

10. Honingh S, Van Weert G, Reuter M (2000) Turning blast furnace dust into a source of zinc and lead units: a progress report on testwork at Corus ijmuiden. In: Fourth international symposium on recycling of metals and engineered materials, pp 313-327.

11. Itoh Y, Fieser AH (1982) Zinc removal from blast furnace dust. Iron Steel Eng 59:33-36

12. Jeon JG, Jin SJ (2002) Posco's achievment for the recycling of sludge. SEAISI Q 31:53-59

13. Uno S, Umetsu Y, Ohmizu M, Munakata S (1979) Dezincing equipment and operation based on wet classification of wetcleaned BF dust. Nippon Steel Tech Rep (Overseas) 13:80-85

14. Vereš J, Lovás M, Jakabský Š, Šepelák V, Hredzák S (2012) Characterization of blast furnace sludge and removal of zinc by microwave assisted extraction. Hydrometallurgy 129-130:67-77. https://doi.org/10.1016/j.hydromet.2012.09.008

15. Van Herck P, Vandecasteele C, Swennen R, Mortier R (2000) Zinc and lead removal from blast furnace sludge with a hydrometallurgical process. Environ Sci Technol 34:3802-3808. https://doi. org/10.1021/es9910331

16. Steer JM, Griffiths AJ (2013) Investigation of carboxylic acids and non-aqueous solvents for the selective leaching of zinc from blast furnace dust slurry. Hydrometallurgy 140:34-41. https://doi. org/10.1016/j.hydromet.2013.08.011

17. Nishioka K, Maeda T, Shimizu M (2002) Dezincing behavior from iron and steelmaking dusts by microwave heating. ISIJ Int 42:S19-S22. https://doi.org/10.2355/isijinternational.42.Suppl S19

18. Tikka J, Lindfors NO, Bäcklund E (2007) Learning from nature: the tornado process. In: Proceedings of the 6th international heavy minerals conference, pp 1-5

19. Robinson R (2008) Studies in low temperature self-reduction of by-products from integrated iron and steelmaking. Doctoral thesis, p 24

20. Rhodes MJ (2008) Introduction to particle technology. Wiley, London. https://doi.org/10.1002/9780470727102

21. Bryk C, Lu WK (1986) Reduction phenomena in composites of iron-ore concentrates and coals. Ironmak Steelmak 13:70-75 
22. Shivaramakrishna N, Sarkar SB, Prasad KK (1996) The role of internal coal in the reduction of composite pellets. SEAISI Q 25:82-90

23. El-Hussiny NA, Shalabi MEH (2011) A self-reduced intermediate product from iron and steel plants waste materials using briquetting process. Powder Technol 205:217-223. https://doi. org/10.1016/j.powtec.2010.09.017

24. Singh M, Björkman B (2006) Strength of cement-bonded briquettes. Miner Metall Proc 23:203-213

25. Olmo IF, Chacon E, Irabien A (2001) Influence of lead, zinc, iron (III) and chromium(III) oxides on the setting time and strength development of Portland cement. Cem Concr Res 31:1213-1219. https://doi.org/10.1016/S0008-8846(01)00545-2

26. Dutta DK, Bordoloi D, Borthakur PC (1995) Hydration of Portland cement clinker in the presence of carbonaceous materials. Cem Concr Res 25:1095-1102. https://doi.org/10.1016/00088846(95)00104-K

27. Ahmed H, Persson A, Sundqvist L, Biorkman B (2014) Energy efficient recycling of in-plant fines. Int J Chem Nucl Mater Metall Eng 8:522-528

28. Singh M, Björkman B (2007) Testing of cement bonded briquettes under laboratory and blast furnace conditions Part 1-Effect of processing parameters. Ironmak Steelmak 34:30-40. https://doi. org/10.1179/174328106X118071

29. Singh M, Björkman B (2004) Effect of processing parameters on the swelling behaviour of cement-bonded briquettes. ISIJ Int 44:59-68. https://doi.org/10.2355/isijinternational.44.59

30. El Kasabgy T, Lu WK (1980) The influence of calcia and magnesia in wustite on the kinetics of metallization and iron whisker formation. Metall Trans B 11:409-414. https://doi.org/10.1007/ BF02676884

31. Wang HT, Sohn HY (2011) Effect of $\mathrm{CaO}$ and $\mathrm{SiO}_{2}$ on swelling and iron whisker formation during reduction of iron oxide compact. Ironmak Steelmak 38:447-452. https://doi. org/10.1179/1743281211Y.0000000022

32. Li GH, Tang ZK, Zhang YB, Cui ZX, Jiang T (2010) Reduction swelling behaviour of haematite/magnetite agglomerates with addition of $\mathrm{MgO}$ and $\mathrm{CaO}$. Ironmak Steelmak 37:393-397. https ://doi.org/10.1179/030192310X12690127076352

33. Sharma T, Prakash B (1993) Effect of firing condition and ingredients on the swelling behaviour of iron ore pellets. ISIJ Int 33:446453. https://doi.org/10.2355/isijinternational.33.446

34. Fredriksson H, Svensson IL (1974) Mechanism of catastrophic swelling of cold-bonded pellets. Scand J Metall 3:185-192
35. Wang H, Sohn HY (2012) Effects of reducing gas on swelling and iron whisker formation during reduction of iron oxide compact. Steel Res Int 83:903-909. https://doi.org/10.1002/srin.201200054

36. Seaton CE, Foster JS, Velasco J (1983) Structural changes occurring during reduction of hematite and magnetite pellets containing coal char. Trans ISIJ 23:497-503

37. Nascimento RC, Movrão MB, Capocchi JDT (1998) Ruductionswelling behaviour of pellets bearing iron ore and charcoal. Can Metall Q 37:441-448. https://doi.org/10.1179/cmq.1998.37.5.441

38. Abdel Halim KS, Bahgat M, El-Kalesh A, Nasr MI (2009) Metallic iron whisker formation and growth during iron oxide reduction: basicity effect. Ironmak Steelmak 36:631-640. https://doi. org/10.1179/174328109X463020

39. Alonso C, Fernandez L (2004) Dehydration and rehydration processes of cement paste exposed to high temperature environments. J Mater Sci 39:3015-3024. https://doi.org/10.1023/ B:JMSC.0000025827.65956.18

40. Ahmed HM, Persson A, Sundqvist-Ökvist L, Björkman B (2015) Reduction behaviour of self-reducing blends of in-plant fines in inert atmosphere. ISIJ Int 55:2082-2089. https://doi.org/10.2355/ isijinternational.ISIJINT-2015-182

41. VDEh (1995) Slag atlas. Verlag Stahleisen GmbH, Düsseldorf

42. Singh M, Björkman B (2004) Effect of reduction conditions on the swelling behaviour of cement-bonded briquettes. ISIJ Int. 44:294-303. https://doi.org/10.2355/isijinternational.44.294

43. Hooey PL, Bodén A, Wang C, Grip CE, Jansson B (2010) Design and application of a spreadsheet-based model of the blast furnace factory. ISIJ Int 50:924-930. https://doi.org/10.2355/isijintern ational.50.924

44. Sterneland J, Andersson MAT, Jönsson PG (2003) Comparison of iron ore reduction in experimental blast furnace and laboratory scale simulation of blast furnace process. Ironmak Steelmak 30:313-327. https://doi.org/10.1179/030192303225003980

45. Hooey L, Sköld B, Sundqvist-Ökvist L, Seppänen M, Zuo G (2005) LKAB's experimental blast furnace-the learning curve. In: The 5th European coke- and ironmaking congress, pp 12-15.

46. Yokoyama H, Higuchi K, Ito T, Oshio A (2012) Decrease in carbon consumption of a commercial blast furnace by using carbon composite iron ore. ISIJ Int 52:601-609. https://doi.org/10.2355/ tetsutohagane.100.601

Publisher's Note Springer Nature remains neutral with regard to jurisdictional claims in published maps and institutional affiliations. 